\title{
ВЕРА В СПРАВЕДЛИВЫЙ МИР, МУЖСКИЕ НОРМАТИВНЫЕ УСТАНОВКИ И АТРИБУЦИЯ ВИНЫ ЖЕРТВАМ ПРЕСТУПЛЕНИЯ
}

\author{
Е.В. УЛЫБИНА \\ ${ }^{a}$ Российская академия народного хозяйства и государственной службы при Президенте \\ Российской Федеращии, 119571, Россия, Москва, пр. Вернадского, 82-84
}

\begin{abstract}
Резюме
Работа посвящена эмпирическому изучению веры в справедливый мир (ВСМ), принятия мужских нормативных установок (МНУ) и оценки окружающими, мужчинами и женщинами, атрибуции вины жертвам изнасилования. В исследовании участвовали 1038 респондентов в возрасте от 18 до 70 лет (630 женщин), заполнявших анкету онлайн. Анкета включала опросник МНУ (Клецина, Иоффе, 2013), опросник ВСМ (Нартова-Бочавер и др., 2013), позволяющий измерить уровень веры в справедливость мира для всех (ВСМобщ) и уровень веры в справедливость мира для себя (ВСМличн), а также виньетку, содержащую рассказ о преступлениях равной тяжести, половом (изнасиловании) либо неполовом (разбое), жертвой во всех случаях была девушка, преступником - мужчина. Результаты показали, что и мужчины, и женщины приписывают жертвам полового и неполового преступления равную вину, оценка вины прямо связана с МНУ, ВСМобщ и ожидаемым обвинением со стороны окружающих. Согласно результатам регрессионного анализа, уровень атрибуции вины жертве во всех случаях связан с уровнем принятия МНУ и ожидаемого отношения, и только в подвыборке мужчин в атрибуцию вины жертве изнасилования вносит вклад с наименьшей значимостью уровень ВСМобщ. И принятие МНУ, и ожидаемое обвинение со стороны других отражают представление о существующей социальной реальности, а ВСМобщ характеризует субъективную оценку справедливости этой социальной реальности. Таким образом, большая детерминированность оценки вины жертвы уровнем МНУ и ожидаемого обвинения, чем ВСМобщ, позволяет говорить о стремлении респондентов скорее избежать противоречий с социальной реальностью, чем сохранить оценку реальности как справедливой.
\end{abstract}

Ключевые слова: вера в справедливый мир, мужские нормативные установки, атрибуция вины жертве преступления, ожидаемое отношение к жертве.

Выявление факторов, оказывающих влияние на отношение к жертвам преступлений, имеет высокую значимость, определяемую возможностью использования их как для предотвращения преступлений, так и для защиты жертвы от потенциального негативного отношения и обвинений, усугубляющих вред, уже причиненный преступником. Особую остроту эта проблема приобретает, когда речь идет о жертвах изнасилований. Изнасилования обладают высокой 
латентностью, порядка 87-90\% (Горбачев, 2016, с. 66), в частности, потому что жертвы боятся огласки и неизбежного, по их мнению, негативного отношения окружающих. По словам юриста М. Давтян, «стать жертвой сексуального насилия - это большой позор. ...Быть насильником сегодня не так позорно, как быть изнасилованной» (Меркурьева, 2015). Существующие негативные установки по отношению к жертвам изнасилования определяют актуальность вопроса о связи ожидаемого со стороны окружающих обвинения жертвы с собственным отношением к ней и вклада ожидаемого отношения среди других факторов, связанных с обвинением жертвы.

Феномен обвинения жертв изнасилования был и остается предметом множества исследований (см.: Grubb, Harrower, 2008; Grubb, Turner, 2012). При этом характеристики жертвы, влияющие на обвинение (внешний вид, поведение, социальный статус, собственный опыт переживания насилия и др.), изучены достаточно подробно, в то время как характеристики наблюдателей - тех, кто оценивает вину жертвы со стороны, - изучены меньше (van der Bruggen, Grubb, 2014).

Травматичность существующего в обществе отношения к жертвам изнасилования делает особенно актуальным вопрос о том, отражает ли обвинение жертвы преимущественно потребность сохранить непротиворечивый субъективный образ справедливого мира (BCM) или же стремление избежать противоречий с мнением большинства. Вопрос об относительной значимости этих факторов представляет интерес как в связи с пониманием природы негативного отношения к жертве, так и в связи с определением направления работы по коррекции отношения к жертвам.

\section{Вера в справедливый мир}

Вера в справедливый мир (ВСМ) «представляет собой общую мировоззренческую установку (часто называемую заблуждением или иллюзией), в соответствии с которой люди убеждены в том, что мир устроен упорядоченно и корректно, представляет собой такое место, где каждый человек, в конечном итоге, получает то, что заслуживает: и награды, и наказания» (НартоваБочавер, Астанина, 2014, с. 18). М. Лернер, обобщая результаты своих экспериментов (Lerner, 1977; Lerner, Miller, 1978), предположил, что тенденция наблюдателей оправдывать несправедливое распределение наград и наказаний, приписывая заслуги награжденным и обвиняя наказанных, связана со стремлением сохранить образ справедливого мира, в котором с хорошими людьми ничего плохого случиться не может, а несчастья - это следствие собственных ошибок или плохих дел. Эта иллюзия дает адаптивные преимущества и является неотъемлемой частью нормального развития (Lerner, 1977). ВСМ формируется на основе внутрипсихической потребности, связанной с инвестициями в долгосрочные цели, и опыта переживания несправедливости и под влиянием социального обучения (Hafer, Sutton, 2016).

После создания методики измерения индивидуальных различий в выраженности BCM (Rubin, Peplau, 1975) адаптивный характер веры в справедливость 
был подтвержден. ВСМ способствует достижению отдаленных целей и смягчает действие стресса (Tomaka, Blascovich, 1994), связана с альтруизмом (Bierhoff et al., 1991; DePalma et al., 1999; Zuckerman, 1975), межличностным доверием (Bègue, 2002), доверием к государственным структурам (Zuckerman, Gerbasi, 1977). Люди, видящие мир как понятный и предсказуемый, доверяют миру и другим людям, оказывают помощь и рассчитывают на взаимность.

Но так как реальный мир сложнее, то страдания невинных жертв, особенно если они не могут быть легко смягчены (Rubin, Peplau, 1975), ставят под сомнение образ справедливого мира, и для того, чтобы его защитить, люди с высокими показателями ВСМ, считая, что каждый получает то, что заслужил, приписывают бо́льшую вину жертвам изнасилования (Pinciotti, Orcutt, 2017) и проявляют меньше сочувствия мигрантам (Dalbert, Yamauchi, 1994), инвалидам (Furnham, 1995), бездомным (Guzewicz, Takooshian, 1992), бедным (Smith, 1985) и другим людям, оказавшимся в неблагоприятных обстоятельствах (Furnham, 2003; Furnham, Procter, 1989; Rubin, Peplau, 1975).

Позже в качестве отдельных шкал были выделены вера в справедливость мира для себя лично (ВСМличн) и вера в справедливость мира для всех (ВСМобщ) (Dalbert, et al., 2001; Lipkus et al., 1996); хотя эти шкалы и коррелируют друг с другом, они выполняют разные функции. Психосоциальной адаптации людей способствует ВСМличн, связанная с положительным самовосприятием и продуктивными стратегиями преодоления стресса (Bègue, Bastounis, 2003; Lipkus et al., 1996; Dalbert, 1999), со способностью прощать себя и других (Strelan, 2007), помогать малоимущим (Bègue et al., 2008). A BCМобщ положительно связана с более строгим отношением к нарушителям (Bègue, Bastounis, 2003), с негативным отношением к пожилым и бедным (Sutton, Douglas, 2005; Bègue, Bastounis, 2003) и отрицательно связана с благотворительностью (Bègue et al., 2008), так как справедливый в целом мир не предполагает незаслуженных страданий, а значит, во всех бедах виноваты сами пострадавшие.

Однако, как показывают исследования, ВСМ не может сама по себе объяснить отношение к жертве изнасилования (van der Bruggen, Grubb, 2014), это не единственный и даже не всегда самый значимый фактор, вносящий вклад в обвинение. Так, например, уровень консерватизма и ориентация на социальное доминирование вносят больший вклад в обвинение жертвы изнасилования, чем BCM (Lambert, Raichle, 2000). Люди с консервативными взглядами, по мнению ряда авторов, склонны поддерживать традиционную систему межгендерного доминирования, и обвинение женщины как жертвы закрепляет право мужчин на реализацию власти.

\section{Отношение к женщине как жертве}

Многочисленные исследования показывают, что отношение к женщине, жертве изнасилования, во многом определяется гендерными стереотипами, так как ситуация затрагивает одновременно иллюзию правильности мироустройства вообще и представление о правильности традиционных межгендерных отношений. Традиционная культура, закрепляя гендерную иерархию, поддер- 
живает и право мужчин на насилие, которое «опирается на патриархальные общественные ценности, подчеркивающие главенство сильного и подчинение слабого (особенно половым путем)» (Андронникова, 2015). Люди с традиционными взглядами на гендерные роли, как показывают имеющиеся данные (см.: Андронникова, 2015; Anderson et al., 1997; De Judicibus, McCabe, 2001; Grubb, Turner, 2012; Koepke et al., 2014; Murnen et al., 2002; Truman et al., 1996; Willis et al., 1996), в большей степени склонны оправдывать насилие в отношении женщин вообще и сексуальное насилие в частности, приписывать жертвам значительную вину за происшедшее. Сексуальное насилие по отношению к женщинам опосредовано ощущением «мужского права», чувства, что потребности мужчин имеют приоритет над потребностями женщин, а социальная роль мужчин позволяет ожидать от женщин удовлетворения их потребностей, включая сексуальные (Hill, Fischer, 2001). При этом традиционный взгляд на гендерные роли вносит больший вклад в приписывание вины жертве изнасилования, чем пол участников исследования (Sims et al., 2007), и женщины, разделяющие ценности гендерной иерархии, соглашаются с правом мужчин проявлять насилие по отношению к женщинам. Чем выше уверенность в оправданности и справедливости гендерной иерархии, тем с большей вероятностью можно ожидать и оправдания насилия со стороны мужчин по отношению к женщинам (Hockett et al., 2009; Hockett et al., 2016). Это согласуется с исследованиями, показывающими прямую связь сексизма с принятием насилия по отношению к женщинам (Glick, Fiske, 1996; Russell, Trigg, 2004; Sakallı-Uğurlu, Glick, 2003).

\section{Мужские нормативные установки}

Степень согласия с гендерными стереотипами отражает, в частности, уровень принятия мужских нормативных установок (МНУ). Изучение МНУ берет начало в работах Э. Томпсона и Дж. Плека, которые в 1986 г. предложили опросник для измерения согласия с мужскими нормами - вариантом социальных норм, обобщающих существующие в культуре ожидания относительно поведения мужчин, предписывающих и запрещающих то, что мужчины должны чувствовать и делать (Thompson, Pleck, 1986). В предложенном ими подходе «маскулинность» рассматривается как социальный конструкт, при анализе которого внимание фокусируется на социальных факторах, определяющих содержание представлений о «настоящем мужчине», а формирование маскулинности происходит за счет социального научения при наблюдении за тем, что общество считает приемлемым или неприемлемым для мужчины (Mahalik et al., 2003).

Идеологии маскулинности достаточно разнообразны (см.: Levant, Richmond, 2008; Mahalik et al., 2003; Thompson, Bennett, 2015), можно говорить об общем ядре стандартов, связанных с традиционной мужской ролью (Pleck, 1995). Традиционная мужская нормативность предполагает антиженственность - стремление избежать сходства с женщиной, право мужчины на власть, склонность к риску и проявлению силы (Thompson, Pleck, 1986), она исключает гендерное равенство (Davis, Greenstein, 2009), в результате образ 
традиционного «настоящего мужчины» строится на «мужской доминантности и оппозиции всему женскому» (Клецина, Иоффе, 2017, с. 32).

Содержание МНУ имплицитно допускает возможность насилия по отношению к женщинам, и, согласно обзору Т. Мура и Г. Стюарта (Moore, Stuart, 2005), показатели нормативности входят в число 4 из 10 рассмотренных авторами измерений маскулинности, обладающих средней или сильной вероятностью предсказания насилия по отношению к женщинам со стороны интимных партнеров.

\section{Взаимодействие ВСМ и гендерных стереотипов при оценке вины жертвы}

Анализ взаимодействия вкладов ВСМ и гендерных стереотипов при оценке вины жертвы изнасилования показывает, что оценка виновности жертвы полового преступления осуществляется, прежде всего, с гендерных позиций, а вклад BCM либо меньше, чем вклад гендерных стереотипов (Adolfsson, Strömwall, 2017; Sakallı-Uğurlu et al., 2007; Valor-Segura et al., 2011; Yamawaki et al., 2009), либо совсем не значим (Brems, Wagner, 1994; Hammond et al., 2011). ВСМ оценивает степень соблюдения правил в мире в целом, гендерные стереотипы определяют правила в межгендерных отношениях, и, когда речь идет об оценке межгендерной ситуации, вклад правил, регулирующих частную область, выше, чем правил, описывающих мир в целом. А в эгалитарных культурах ни враждебный сексизм, ни ВСМ не прогнозируют приписывание вины жертве, и значимый вклад в обвинение вносит только доброжелательный сексизм - убеждение в том, что женщины слабы и нуждаются в защите и опеке со стороны сильных мужчин (Pedersen, Strömwall, 2013). Для людей с традиционными взглядами невиновность жертвы изнасилования несет меньшую угрозу образу справедливого мира в целом, чем образу справедливости традиционных гендерных стереотипов, в то время как в эгалитарной среде невинность жертвы изнасилования не воспринимается как угроза ни отсутствующей или слабо выраженной гендерной иерархии, ни представлению о справедливости мира. Различие связей ВСМ и гендерных стереотипов с обвинением жертвы в зависимости от культурного контекста показывает влияние доминирующих в обществе убеждений о межгендерных отношениях на собственные суждения респондентов.

\section{Влияние мнения окружающих}

Принимая решение в ситуации неопределенности люди, ориентируются, в частности, на мнение окружающих. Эксперименты С. Аша (Asch, 1956; Bond, Smith, 1996) показали, что люди склонны изменять свои оценки в сторону согласия с оценками большинства, в том числе и при анонимном ответе (Deutsch, Gerard, 1955). В сложной, неоднозначной ситуации суждения других воспринимаются как более достоверный источник информации о реальности, так как если определенным образом думает и поступает большинство, то это, вероятно, оправданно и адаптивно (Cialdini et al., 1990; Lönnqvist et al., 2009). Согласие с мнением 
большинства дает ощущение принадлежности к группе, поддерживает идентичность (Abrams et al., 1990; Hogg, Reid, 2006; Postmes et al., 2005), а принадлежность к большинству, в свою очередь, повышает самооценку (Pool et al., 1998).

Отношение к изнасилованию во многом поддерживается за счет транслируемого культурой мифа об изнасиловании - представлений о том, что жертва сама хочет быть изнасилованной, что мужчина имеет право проявлять силу и что «порядочные женщины» застрахованы от сексуальной агрессии (Burt, 1980), a знание о том, что этот миф поддерживается большинством, повышает и принятие мифа участниками исследования (Bohner et al., 2006; Bohner et al., 2010; Eyssel et al., 2006).

Влияние знания об отношении окружающих к жертве изнасилования на арибуцию вины жертве только начинает изучаться. В работе И. Андерсон и Э. Лайонс (Anderson, Lyons, 2005) испытуемые читали газетный отчет об изнасиловании, в одном варианте которого говорилось о том, что друзья и знакомые выразили жертве поддержку, в другом - что близкие не поддержали ее. Результаты показали, что читавшие о поддержке жертвы осудили ее гораздо меньше, чем те, кто читал про отсутствие поддержки. Последующие исследования, в которых варьировались уровни поддержки и рассматривалась роль поддержки при учете других факторов (Brown, Testa, 2008; Pinciotti, Orcutt, 2017), подтвердили значимость влияния знания об отношении к жертве со стороны близких на оценку вины жертвы участниками исследования.

Однако в реальной ситуации люди обычно не знают о том, как отнеслись к жертве близкие, но, как правило, у них есть представление о том, как могут отнестись к жертве окружающие, и это ожидаемое отношение, как предполагается, может быть связано и с собственной оценкой вины жертвы.

\section{Цель исследования}

Анализ предыдущих исследований показывает, что в случае обвинения жертвы изнасилования больший вклад в приписывание вины вносит согласие с традиционными гендерными стереотипами, чем показатели ВСМ/ ВСМобщ, респонденты в большей степени стремятся сохранить представление о справедливости традиционной межгендерной иерархии, чем мира в целом.

Гендерные стереотипы, в частности МНУ как элемент социальных норм, транслируются культурой, и согласие с ними отражает, с одной стороны, согласие с социальными нормами в области межгендерных отношений, а с другой соответствие личным установкам в этой области. Принятие гендерных стереотипов и ориентацию на актуальное мнение окружающих можно рассматривать как формы конформизма, они не эквивалентны друг другу. Люди с высокими показателями гендерных стереотипов могут жить в окружении, не осуждающем жертву, а люди, не поддерживающие стереотипы, - в обществе, осуждающем жертв. Но вопрос о том, что больше вносит вклад в обвинение жертв изнасилования- ориентация на актуальное мнение большинства о жертве или собственные представления респондентов о межгендерных отношениях, - остается открытым. 
Слабо изучен и вопрос о значимости межгендерной позиции и ориентации на мнение окружающих при обвинении женщин, жертв изнасилования, и женщин, жертв неполовой физической агрессии со стороны мужчин. Имеющиеся немногочисленные и противоречивые данные не позволяют говорить об устойчивости тенденции большего обвинения жертвы полового или неполового преступления. Так, в некоторых случаях (Brems, Wagner, 1994; Howard, 1984; Kanekar et al., 1985) жертве грабежа приписывали бо́льшую вину, чем жертве изнасилования, а в других (Bieneck, Krahé, 2011) получены данные о том, что жертву изнасилования обвиняли больше. Можно предположить, что факторы, связанные с гендерными стереотипами и существующим убеждением о негативном отношении к жертвам изнасилования, будут вносить меньший вклад в обвинение жертвы неполового преступления, чем в обвинение жертв изнасилования.

\section{Гипотезы}

Проведенный анализ исследований по проблеме позволил сформулировать следующие гипотезы:

1. Приписывание вины жертве изнасилования и у мужчин, и у женщин прямо связано с ВСМобщ, МНУ и ожидаемым отношением к жертве окружающих (в дальнейшем - ожидаемым отношением); МНУ и ожидаемое отношение вносят больший вклад в приписывание вины, чем ВСМобщ и у мужчин, и у женщин.

2. Приписывание вины жертве разбоя и у мужчин, и у женщин прямо связано с ВСМобщ, МНУ и ожидаемым отношением; ВСМобщ вносит больший вклад в отношение к жертве разбоя, чем МНУ и ожидаемое отношение.

\section{Участники и методы исследования}

Респонденты - 1038 человек (630 женщин, 408 мужчин) в возрасте от 18 до 70 лет - заполняли онлайн-форму, размещенную в социальных сетях. Сбор данных проходил с июня по август 2017 г. Участникам предлагалась анкета, включающая опросник МНУ (Клецина, Иоффе, 2013), опросник ВСМ (Нартова-Бочавер и др., 2013) и виньетку, имеющую две формы. Опросник МНУ «предназначен для выявления системы убеждений и установок относительно маскулинности и мужских ролей, которая побуждает действовать в соответствии с этими установками и избегать того, что ими не поощряется» (Клецина, Иоффе, 2013). Опросник представляет собой адаптацию опросника «Мужские нормативные установки» (The Male Attitude Norms Inventory-II) P. Луйта (Luyt, 2005) и включает 40 утверждений, согласие с которыми оценивается по 5-балльной шкале Лайкерта (примеры утверждений: «Мужчина должен быть жестким», «Именно мужчина должен принимать все окончательные решения в семье», «Мужчина успешен, если он хорошо зарабатывает»).

Опросник ВСМ (Нартова-Бочавер и др., 2013) состоит из 13 утверждений, 7 из которых составляют шкалу ВСМличн (примеры утверждений: «Как пра- 
вило, жизнь ко мне справедлива», «Я верю, что обычно получаю то, что заслуживаю»), а 6 - шкалу ВСМобщ («Я считаю, что, по большому счету, люди получают то, что заслуживают», «Я уверен, что справедливость всегда побеждает несправедливость»). Согласие с утверждениями оценивается по 7-балльной шкале Лайкерта.

Для оценки отношения к жертве использовалась следующая виньетка: «Девушка возвращалась домой после вечеринки, где немного выпила. У нее было хорошее настроение. По дороге домой она познакомилась с симпатичным молодым человеком, который предложил ее проводить. Молодой человек был вежлив, не навязчив, и девушка согласилась. Когда они проходили мимо пустыря, молодой человек (1-й вариант) толкнул ее в кусты и, угрожая ножом, изнасиловал; (2-й вариант) ударил ее кастетом по голове, причинив тяжкое телесное повреждение, вырвал сумку с деньгами и документами и убежал. Рассказ об истории без упоминания имени девушки попал в социальные сети и вызвал обсуждение. Высказывались разные мнения о поведении девушки и о том, что ей нужно было делать. Оцените степень согласия с каждым утверждением:

1. Девушка сама виновата в том, что с ней произошло.

2. Если девушка расскажет о происшедшем, то многие сочтут, что она сама виновата».

Формулировка шкалы для оценки виновности жертвы была предложена в той форме, в которой она могла бы звучать при обсуждении ситуации в сети. Участникам предлагалось оценить степень согласия с каждым утверждением по 7-балльной шкале от 1 - «Совершенно не согласен» до 7 - «Совершенно согласен».

Участникам в случайном порядке предлагался либо 1-й вариант виньетки, либо 2-й. Половина анкет начиналась с одного из двух вариантов виньетки, а другая - с опросников, а виньетка располагалась в конце, перед вопросами о возрасте и поле участников.

Оба преступления, изнасилование и разбой, предполагают равную меру наказания, уравнены по степени тяжести и максимальному сроку наказания, в обоих случаях женщина, обычно более слабая, чем мужчина, имеет меньшие возможности защитить себя физически, описание обоих преступлений включает элемент романтического знакомства. И различие связано только с фактом сексуального аспекта агрессии.

\section{Изложение результатов}

Как показал анализ полученных данных (таблица 1), различия в уровне ВСМобщ и ВСМличн мужчин и женщин не значимы, уровень МНУ у мужчин ожидаемо выше, чем у женщин. К сожалению, не удалось собрать уравненную по возрасту выборку, в полученных данных мужчины значимо старше женщин.

Показатели уровня согласованности шкал опросника веры в справедливый мир достаточно высокие и близки данным, полученным ранее в онлайн-опросе отечественных респондентов (Gulevich, Sarieva, 2015). 
И в подвыборке мужчин, и в подвыборке женщин различия в приписывании вины жертвам полового и неполового преступления не значимы (таблица 2). Жертве изнасилования женщины приписывают значимо меньшую вину, чем мужчины $(t=3.182, p<0.01)$, различия в приписывании вины жертве разбоя не значимы. Ожидаемое обвинение жертвы со стороны других во всех случаях значимо выше собственного обвинения на уровне $p<0.000$.

В таблице 3 представлены результаты корреляционного анализа вины жертвы разбоя и жертвы изнасилования и ожидаемого обвинения со стороны других с возрастом респондентов, МНУ и шкалами ВСМ у мужчин и женщин.

Таблица 1

Описательная статистика показателей возраста, МНУ, ВСМличн и ВСМобщ у мужчин и женщин

\begin{tabular}{|c|c|c|c|c|c|c|}
\hline \multirow{2}{*}{ Переменные } & \multicolumn{2}{|c|}{ Женщины } & \multicolumn{2}{|c|}{ Мужчины } & \multirow{2}{*}{$\begin{array}{l}\text { t-критерий } \\
\text { Стьюдента }\end{array}$} & \multirow{2}{*}{$\alpha$} \\
\hline & M & $\mathrm{SD}$ & M & $\mathrm{SD}$ & & \\
\hline Возраст & 34.557 & 16.511 & 47.431 & 13.887 & $-13.043^{* * *}$ & \\
\hline $\begin{array}{l}\text { Общее принятие мужских } \\
\text { нормативных установок }\end{array}$ & 112.798 & 24.120 & 129.103 & 21.403 & $-11.112^{* * *}$ & 0.90 \\
\hline $\begin{array}{l}\text { Вера в справедливость мира } \\
\text { для себя лично }\end{array}$ & 34.129 & 9.024 & 34.706 & 8.875 & -1.013 & 0.91 \\
\hline $\begin{array}{l}\text { Вера в справедливость мира } \\
\text { для всех }\end{array}$ & 21.790 & 8.100 & 22.248 & 7.888 & -0.897 & 0.80 \\
\hline
\end{tabular}

$* * * p<0.001$.

Таблица 2

Различия в уровне приписывания вины жертве и ожидаемом обвинении жертвы со стороны других у мужчин и женщин

\begin{tabular}{|c|c|c|c|c|c|}
\hline \multirow{2}{*}{$\begin{array}{r}\text { Вид преступления } \\
\text { Согласие с утверждениями }\end{array}$} & \multicolumn{2}{|c|}{ Изнасилование } & \multicolumn{2}{|c|}{ Разбой } & \multirow{2}{*}{$\begin{array}{l}\text { t-критерий } \\
\text { Стьюдента }\end{array}$} \\
\hline & M & SD & M & SD & \\
\hline \multicolumn{6}{|c|}{ Женщины } \\
\hline $\begin{array}{l}\text { Девушка сама виновата в } \\
\text { случившемся }\end{array}$ & 2.823 & 1.843 & 3.034 & 1.961 & -1.396 \\
\hline $\begin{array}{l}\text { Если она расскажет о случившем- } \\
\text { ся, другие сочтут ее виноватой }\end{array}$ & 4.752 & 1.783 & 4.531 & 1.893 & 1.503 \\
\hline \multicolumn{6}{|c|}{ Мужчины } \\
\hline $\begin{array}{l}\text { Девушка сама виновата в } \\
\text { случившемся }\end{array}$ & 3.382 & 2.106 & 3.353 & 2.099 & 0.141 \\
\hline $\begin{array}{l}\text { Если она расскажет о случившем- } \\
\text { ся, другие сочтут ее виноватой }\end{array}$ & 4.623 & 1.883 & 4.142 & 1.903 & $2.563^{*}$ \\
\hline
\end{tabular}

$* p<0.05$. 
Для оценки относительного вклада возраста, МНУ, ВСМобщ, ВСМличн и ожидаемого обвинения со стороны других в приписывание вины жертве был использован регрессионный анализ с прямым пошаговым включением (таблица 4).

\section{Обсуждение результатов}

МНУ и ожидаемое обвинение вносят больший вклад в приписывание вины жертве, чем ВСМобщ, во всех случаях, что подтверждает 1-ю гипотезу и не подтверждает 2-ю. Оба преступления оцениваются, прежде всего, в гендерном контексте как вариант насилия мужчины по отношению к женщине и с опорой на ожидаемое общественное мнение.

Больший вклад МНУ в оценку женщины как жертвы соответствует выявленной ранее тенденции, согласно которой вклад гендерных стереотипов в обвинение женщины как жертвы изнасилования выше, чем вклад иллюзии справедливости. Полученные результаты позволяют предполагать, что эта

Таблица 3

Корреляции оценок вины жертвы разбоя и жертвы изнасилования и ожидаемого обвинения со стороны других с возрастом респондентов, МНУ и шкалами ВСМ у мужчин и женщин

\begin{tabular}{|c|c|c|c|c|}
\hline \multirow{2}{*}{$\begin{array}{c}\text { Пол респондентов } \\
\text { Показатели }\end{array}$} & \multicolumn{2}{|c|}{ Женщины } & \multicolumn{2}{|c|}{ Мужчины } \\
\hline & $\begin{array}{c}\text { Она сама } \\
\text { виновата в } \\
\text { случившемся }\end{array}$ & $\begin{array}{l}\text { Ожидаемое } \\
\text { обвинение }\end{array}$ & $\begin{array}{c}\text { Она сама } \\
\text { виновата в } \\
\text { случившемся }\end{array}$ & $\begin{array}{l}\text { Ожидаемое } \\
\text { обвинение }\end{array}$ \\
\hline \multicolumn{5}{|c|}{ Изнасилование } \\
\hline Возраст & $0.139 *$ & 0.080 & 0.124 & $0.181^{* *}$ \\
\hline $\begin{array}{l}\text { Общее принятие мужских } \\
\text { нормативных установок }\end{array}$ & $0.393 * * *$ & 0.051 & $0.404^{* * *}$ & $0.217^{* *}$ \\
\hline $\begin{array}{l}\text { Вера в справедливость мира } \\
\text { для себя лично }\end{array}$ & 0.000 & $-0.127^{*}$ & 0.050 & 0.018 \\
\hline $\begin{array}{l}\text { Вера в справедливость мира } \\
\text { для всех }\end{array}$ & $0.158 * *$ & $-0.115^{*}$ & $0.226^{* *}$ & 0.072 \\
\hline Ожидаемое обвинение & $0.154^{* *}$ & & $0.325^{* * *}$ & \\
\hline \multicolumn{5}{|c|}{ Разбой } \\
\hline Возраст & $0.270 * * *$ & 0.082 & 0.121 & 0.065 \\
\hline $\begin{array}{l}\text { Общее принятие мужских } \\
\text { нормативных установок }\end{array}$ & $0.497 * * *$ & 0.060 & $0.306^{* * *}$ & 0.129 \\
\hline $\begin{array}{l}\text { Вера в справедливость мира } \\
\text { для себя лично }\end{array}$ & 0.031 & $-0.127^{*}$ & 0.121 & 0.025 \\
\hline $\begin{array}{l}\text { Вера в справедливость мира } \\
\text { для всех }\end{array}$ & $0.220 * * *$ & -0.092 & $0.187^{* *}$ & 0.025 \\
\hline Ожидаемое обвинение & $0.275^{* * *}$ & & $0.440 * * *$ & \\
\hline
\end{tabular}

$$
{ }^{*} p<0.05,{ }^{* *} p<0.01,{ }^{* * *} p<0.001 .
$$


Таблица 4

Результаты множественного регрессионного анализа с прямым пошаговым включением, в котором в качестве предикторов были включены возраст, МНУ, ВСМобщ, ВСМличн и ожидаемое обвинение, а в качестве зависимой переменной - приписывание вины жертве

\begin{tabular}{|l|c|c|c|c|}
\hline \multicolumn{1}{|c|}{ Предикторы } & $\mathbf{b}^{*}$ & $\boldsymbol{t}$ & $\boldsymbol{p}$ & $\boldsymbol{R}^{\mathbf{2}}\left(\mathbf{R}_{\text {скорект }}\right)$ \\
\hline $\begin{array}{l}\text { Женщины, приписывание вины жертве } \\
\text { изнасилования }\end{array}$ & & & & 0.180 (0.172) \\
\hline МНУ & 0.364 & 6.828 & 0.000 & \\
\hline Ожидаемое обвинение & 0.146 & 2.792 & 0.006 & \\
\hline Женщины, приписывание вины жертве разбоя & & & & $0.318(0.309)$ \\
\hline МНУ & 0.422 & 7.835 & 0.000 & \\
\hline Ожидаемое обвинение & 0.250 & 5.308 & 0.000 & \\
\hline $\begin{array}{l}\text { Мужчины, приписывание вины жертве } \\
\text { изнасилования }\end{array}$ & & & & 0.260 (0.245) \\
\hline МНУ & 0.344 & 5.478 & 0.000 & \\
\hline Ожидаемое обвинение & 0.236 & 3.771 & 0.000 & \\
\hline ВСМобщ & 0.213 & 3.192 & 0.002 & \\
\hline Мужчины, приписывание вины жертве разбоя & & & & $0.266(0.254)$ \\
\hline Ожидаемое обвинение & 0.409 & 6.698 & 0.000 & \\
\hline МНУ & 0.218 & 3.348 & 0.001 & \\
\hline
\end{tabular}

тенденция действует не только по отношению к жертвам полового, но и по отношению к жертвам неполового преступления. Принятие МНУ выполняет двойную функцию: согласие с нормативами мужского поведения предоставляет внутренне согласованный вариант интерпретации ситуации межгендерных отношений, что поддерживает иллюзию понятного и контролируемого мира, основанного на правилах, и одновременно дает чувство единства с социальным окружением, снимает возможные сомнения в правильности собственных оценок ситуации за счет присоединения к социально детерминированным нормативам гендерной роли. В результате интерпретация межгендерного преступления осуществляется в большей степени с опорой на гендерные нормативы, чем на представление об общей справедливости.

Женщинами обе ситуации воспринимаются в равной степени как межгендерные, и приписывание вины жертвам обеих ситуаций служит поддержке традиционных отношений, в которых мужчины обладают силой и властью, а женщины должны соблюдать осторожность в отношениях с мужчинами. Вероятно, это дает женщинам, принимающим традиционные нормы, ощущение возможности контролировать ситуацию и избегать неприятностей при соблюдении правил. В этом случае ссылаться на иллюзию справедливости уже нет необходимости. Для мужчин опора на МНУ как бы оправдывает проявление сексуальной и несексуальной агрессии «мужским правом», что определяет и высокий вклад МНУ в 
приписывание вины жертве изнасилования, и меньший вклад в обвинение жертвы разбоя, так как разбой, даже в ситуации романтического знакомства, сложнее рассматривать как реализацию «мужского права». В результате у мужчин МНУ вносит меньший вклад в обвинение жертвы разбоя, чем ожидаемое обвинение.

Ожидаемое обвинение в среднем выше собственного по отношению ко всем жертвам и у мужчин, и у женщин. Возможно, различие связано со смещенной выборкой, которую составили пользователи социальных сетей, преимущественно фейсбука, ответившие на вопросы, и их показатели не отражают отношения к жертвам всей популяции. А возможно, люди ошибочно приписывают окружающим худшее отношение к жертвам, ориентируясь на бо́льшую представленность этой позиции в СМИ и социальных сетях. Однако природа этого расхождения нуждается в дополнительном изучении.

Ожидаемое обвинение во всех случаях вносит больший вклад в приписывание вины жертвам, чем ОС. Ожидаемое обвинение, как предполагается, связано с характеристиками объективной реальности, отражающими представление о доминирующем в данный момент отношении к жертвам, с которым респонденты могут соглашаться или не соглашаться, считать его справедливым или не справедливым. Ожидаемое обвинение коррелирует с МНУ только у мужчин при оценке жертвы изнасилования. Возможно, для мужчин принятие МНУ как общей маскулинной идеологии не предполагает отличия собственной оценки полового преступления от доминирующей оценки окружающих.

А в выборке женщин ожидаемое обвинение оценивается как в некоторой степени противоречащее справедливости, однако оно тоже вносит больший вклад в обвинение обеих жертв, чем ВСМобщ. И женщины, и мужчины учитывают возможное отношение к жертве при оценке ее вины в большей степени, чем то, насколько вероятная невиновность жертвы будет нарушать образ справедливого для всех мира.

ВСМобщ вносит вклад, наименьший по значимости у мужчин, только в обвинение жертвы изнасилования. Согласно Р. Чалдини с коллегами (Cialdini et al., 1976), приписывание вины жертве связано с ВСМобщ в той степени, в которой респонденты могут идентифицировать себя с агрессором, тем самым как бы оправдывая свое возможное соучастие. Из всех рассмотренных ситуаций только ситуация изнасилования предоставляет возможность для респондентов-мужчин в той или иной степени идентифицироваться с агрессором, и, возможно, обвиняя жертву, они как бы оправдывают всех мужчин.

Полученные результаты позволяют говорить, что и у мужчин, и у женщин оценка вины жертвы полового и неполового преступления в большей степени детерминирована стремлением избежать противоречий с социальной реальностью, представленной гендерными стереотипами и ожидаемым отношением к жертве, чем сохранением образа справедливого мира.

\section{Выводы}

Подтверждено предположение, согласно которому гендерные стереотипы вносят больший вклад в обвинение женщины как жертвы, чем уровень 
ВСМ/ВСМобщ. Показано, что эта тенденция имеет отношение не только к жертвам полового, но и неполового преступления.

Показана связь обвинения жертвы, полового и неполового преступления с ожидаемым отношением со стороны окружающих и у мужчин, и у женщин. Ожидаемое обвинение во всех случаях вносит больший вклад в обвинение жертвы, чем ВСМобщ.

\section{Ограничения и вопросы будущих исследований}

Выборки мужчин и женщин не уравнены по возрасту, мужчины значимо старше, что могло повлиять на различия в структуре связей измеряемых показателей. Респондентами выступали пользователи социальных сетей, преимущественно фейсбука, и выборка не отражает генеральной совокупности в целом.

Объем дисперсии, объясняемой взаимодействием рассматриваемых предикторов, относительно невелик, что позволяет предполагать существование других факторов, связанных с приписыванием вины жертве. В качестве таких факторов могут выступать как содержание личного опыта встречи с насилием, так и личностные особенности респондентов, включая эмоциональный интеллект и эмпатию, терпимость к неопределенности, веру в опасный мир, конформизм, особенности системы ценностей, связанные с конфессиональными и региональными характеристиками респондентов.

\section{Литература}

Андронникова, О. О. (2015). Теоретический анализ основных современных теорий виктимизации, разработанных в рамках зарубежной науки. Вестник Кемеровского государственного университета, 4-1(64), 54-57.

Горбачев, М. А. (2016). Сексуальная преступность в России: криминологическое исследование (Кандидатская диссертация). Московский государственный юридический университет им. О.Е. Кутафина, Москва.

Клецина, И. С., \& Иоффе, Е. В. (2013). Результаты первичного этапа адаптации российского аналога опросника «Мужские нормативные установки». Психологические исследования: электронный научный журнал, 6(32), 6. Режим доступа: http://psystudy.ru

Клецина, И. С., Иоффе, Е. В. (2017). Гендерные нормы как социально-психологический феномен. М.: Проспект.

Меркурьева, А. (2015, 21 октября). А ты как хотела: как в России обращаются с жертвами изнасилования. Афиша Daily. Режим доступа: https://daily.afisha.ru/archive/gorod/people/a-tykak-hotela-kak-v-rossii-obrashchayutsya-s-zhertvami-iznasilovaniya

Нартова-Бочавер, С. К., Астанина, Н. Б. (2014). Психологические проблемы справедливости в зарубежной персонологии: теории и эмпирические исследования. Психологический журнал, 35(1), 16-32.

Нартова-Бочавер, С. К., Подлипняк, М. Б., Хохлова, А. Ю. (2013). Вера в справедливый мир и психологическое благополучие у глухих и слышащих подростков и взрослых. Клиническая $u$ специальная психология, 2(3). Режим доступа: https://psyjournals.ru/files/64003/psyclin_2013_3_Nartova_Hohlova_Podlipnjak.pdf 
Ссылки на зарубежные источники см. в разделе References после англоязычного блока.

Улыбина Елена Викторовна - профессор, кафедра общей психологии, Институт общественных наук, РАНХиГС, доктор психологических наук.

Сфера научных интересов: вера в справедливый мир, гендерная психология, психология личности.

Контакты: evulbn@gmail.com

\title{
Contribution of Belief in a Just World, Male Attitude Norms and Expectant Attitude to Victim in Attribution of Blame to the Female Victim
}

\author{
E.V. Ulybina ${ }^{a}$
}

${ }^{a}$ Russian Presidential Academy of National Economy and Public Administration (RANEPA), 82-84 Prospect Vernadskogo, Moscow, 119571, Russian Federation

\begin{abstract}
The study describes the empirical research on the impact of belief in a just world, acceptance of male normative attitudes and public expectant attitude toward the victim on the victim blaming in rape or robbery on the part of both men and women. One thousand thirty eight respondents aged 18-70 (630 females) filled out an online survey. This survey included the questionnaire on male attitude norms (Kletsina, Ioffe, 2013), the questionnaire on belief in a just world (Nartova-Bochaver and others, 2013), which allowed to estimate the level of belief in a just world for everyone (general justice) and the level of belief in a just world for the self (personal justice), and, at last, the vignette, containing a story either about robbery or rape, with a woman as a victim and a man as a perpetrator. According to the analysis of the obtained data, both male and female respondents put blame on victims of robbery and rape equally; men and women did not differ on victim blaming in cases of robbery in terms of moral evaluation, but men more than women blamed a victim of rape. The results of the stepwise regression analysis showed that in both cases the level of acceptance of male normative attitudes and public expectant attitude make input into the level of victim blaming. The indicator of general justice makes input into the victim blaming in rape only in the subsample of men. The acceptance of both male normative attitudes and public expectant blame reflect the representations of the current social reality, whereas general justice frames the subjective evaluation of this social reality. Therefore, the higher determinacy of the victim blaming by the level of male normative attitudes and expectant blame as opposed to belief in general justice, allows us to assume that people tend more to avoid conflict with social reality than to retain an evaluation of reality as a just one.
\end{abstract}

Keywords: belief in a just world, male normative attitudes, attribution of guilt to the victim of a crime, expectant attitude to the victim. 


\section{References}

Abrams, D., Wetherell, M., Cochrane, S., Hogg, M. A., \& Turner, J. C. (1990). Knowing what to think by knowing who you are: Self categorization and the nature of norm formation, conformity and group polarization. British Journal of Social Psychology, 29(2), 97-119. doi:10.1111/j.20448309.1990.tb00892.x

Adolfsson, K., \& Strömwall, L. A. (2017). Situational variables or beliefs? A multifaceted approach to understanding blame attributions. Psychology, Crime and Law, 23(6), 527-552. doi:10.1080/1068316X.2017.1290236

Anderson, I., \& Lyons, A. (2005). The effect of victims' social support on attributions of blame in female and male rape. Journal of Applied Social Psychology, 35(7), 1400-1417. doi:10.1111/j.15591816.2005.tb02176.x

Anderson, K. B., Cooper, H., \& Okamura, L. (1997). Individual differences and attitudes toward rape: A meta-analytic review. Personality and Social Psychology Bulletin, 23(3), 295-315. doi:10.1177/0146167297233008

Andronnikova, O. O. (2015). Theoretical analysis of the main contemporary theories of victimization developed within foreign science. Vestnik Kemerozskogo Gosudarstvennogo Universiteta, 1(4(64)), 54-57. (in Russian)

Asch, S. E. (1956). Studies of independence and conformity: I. A minority of one against a unanimous majority. Psychological Monographs: General and Applied, 70(9), 1-70. doi:10.1037/h0093718

Bègue, L. (2002). Beliefs in justice and faith in people: Just world, religiosity and interpersonal trust. Personality and Individual Differences, 32(3), 375-382. doi:10.1016/S0191-8869(00)00224-5

Bègue, L., \& Bastounis, M. (2003). Two spheres of belief in justice: Extensive support for the bidimensional model of belief in a just world.Journal of Personality, 71(3), 435-463. doi:10.1111/1467-6494.7103007

Bègue, L., Charmoillaux, M., Cochet, J., Cury, C., \& De Suremain, F. (2008). Altruistic behavior and the bidimensional just world belief. The American Journal of Psychology, 121(1), 47-56. doi: $10.2307 / 20445443$

Bieneck, S., \& Krahé, B. (2011). Blaming the victim and exonerating the perpetrator in cases of rape and robbery: Is there a double standard? Journal of Interpersonal Violence, 26(9), 1785-1797. doi:10.1177/0886260510372945

Bierhoff, H. W., Klein, R., \& Kramp, P. (1991). Evidence for the altruistic personality from data on accident research. Journal of Personality, 59(2), 263-280.

Bohner, G., Pina, A., Tendayi Viki, G., \& Siebler, F. (2010). Using social norms to reduce men's rape proclivity: Perceived rape myth acceptance of out-groups may be more influential than that of ingroups. Psychology, Crime and Law, 16(8), 671-693. doi:10.1080/1068316X.2010.492349

Bohner, G., Siebler, F., \& Schmelcher, J. (2006). Social norms and the likelihood of raping: Perceived rape myth acceptance of others affects men's rape proclivity. Personality and Social Psychology Bulletin, 32(3), 286-297. doi:10.1177/0146167205280912

Bond, R., \& Smith, P. B. (1996). Culture and conformity: A meta-analysis of studies using Asch's (1952b, 1956) line judgment task. Psychological Bulletin, 119(1), 111-137. doi:10.1037/0033-2909.119.1.111

Brems, C., \& Wagner, P. (1994). Blame of victim and perpetrator in rape versus theft. The Journal of Social Psychology, 134(3), 363-374. doi:10.1080/00224545.1994.9711741

Brown, A. L., \& Testa, M. (2008). Social influences on judgments of rape victims: The role of the negative and positive social reactions of others. Sex Roles, 58(7-8), 490-500. doi:10.007/s11199-007-9353-7

Burt, M. (1980). Cultural myths and supports for rape. Journal of Personality and Social Psychology, 38(2), 217-230. doi:10.1037/0022-3514.38.2.217 
Cialdini, R. B., Kenrick, D. T., \& Hoerig, J. H. (1976). Victim derogation in the Lerner paradigm: Just world or just justification? Journal of Personality and Social Psychology, 33(6), 719-724. doi:10.1037/0022-3514.33.6.719

Cialdini, R. B., Reno, R. R., \& Kallgren, C. A. (1990). A focus theory of normative conduct: recycling the concept of norms to reduce littering in public places. Journal of Personality and Social Psychology, 58(6), 1015-1026.

Dalbert, C. (1999). The world is more just for me than generally: About the personal belief in a just world scale's validity. Social Justice Research, 12, 79-98.

Dalbert, C., Lipkus, I. M., Sallay, H., \& Goch, I. (2001). A just and an unjust world: Structure and validity of different world beliefs. Personality and Individual Differences, 30(4), 561-577. doi:10.1016/S0191-8869(00)00055-6

Dalbert, C., \& Yamauchi, L. A. (1994). Belief in a just world and attitudes toward immigrants and foreign workers: A cultural comparison between Hawaii and Germany. Journal of Applied Social Psychology, 24(18), 1612-1626. doi:10.1111/j.1559-1816.1994.tb01565.x

Davis, S. N., \& Greenstein, T. N. (2009). Gender ideology: Components, predictors, and consequences. Annual Review of Sociology, 35, 87-105. doi:10.1146/annurev-soc-070308-115920

De Judicibus, M., \& McCabe, M. P. (2001). Blaming the target of sexual harassment: Impact of gender role, sexist attitudes, and work role. Sex Roles, 44(7), 401-417. doi:10.1023/A:1011926027920

DePalma, M., Madey, S. F., Tillman, T. C., \& Wheeler, J. (1999). Perceived patient responsibility and belief in a just world affect helping. Basic and Applied Psychology, 21, 131-137. doi:10.1207/S15324834BA210205

Deutsch, M., \& Gerard, H. B. (1955). A study of normative and informational social influences upon individual judgment. The Journal of Abnormal and Social Psychology, 51(3), 629-636. doi:10.1037/h0046408

Eyssel, F., Bohner, G., \& Siebler, F. (2006). Perceived rape myth acceptance of others predicts rape proclivity: Social norm or judgmental anchoring? Swiss Journal of Psychology/Schweizerische Zeitschrift für Psychologie/Revue Suisse de Psychologie, 65(2), 93-99. doi:10.1024/1421-0185.65.2.93

Furnham, A. (1995). The just world, charitable giving and attitudes to disability. Personality and Individual Differences, 19(4), 577-583. doi:10.1016/0191-8869(95)00090-S

Furnham, A. (2003). Belief in a just world: Research progress over the past decade. Personality and Individual Differences, 34(5), 795-817. doi:10.1016/S0191-8869(02)00072-7

Furnham, A., \& Procter, E. (1989). Belief in a just world: Review and critique of the individual difference literature. British Journal of Social Psychology, 28(4), 365-384. doi:10.1111/j.20448309.1989.tb00880.x

Glick, P., \& Fiske, S. T. (1996). The ambivalent sexism inventory: Differentiating hostile and benevolent sexism. Journal of Personality and Social Psychology, 70(3), 491-512. doi:10.1037/0022-3514.70.3.491

Gorbachev, M. A. (2016). Seksual'naya prestupnost'v Rossii: kriminologicheskoe issledovanie [Sexual crimes in Russia: a criminological study] (PhD dissertation). Kutafin Moscow State Law University, Moscow, Russian Federation. (in Russian)

Grubb, A., \& Harrower, J. (2008). Attribution of blame in cases of rape: An analysis of participant gender, type of rape and perceived similarity to the victim. Aggression and Violent Behavior, 13(5), 396-405. doi:10.1016/j.avb.2008.06.006

Grubb, A., \& Turner, E. (2012). Attribution of blame in rape cases: A review of the impact of rape myth acceptance, gender role conformity and substance use on victim blaming. Aggression and Violent Behavior, 17(5), 443-452. doi:10.1016/j.avb.2012.06.002 
Gulevich, O. A., \& Sarieva, I. R. (2015). Just world belief and the image of the perfect political leader: the role of national identification. Psychology. Journal of Higher School of Economics, 12(3), 30-40.

Guzewicz, T. D., \& Takooshian, H. (1992). Development of a short-form scale of public attitudes toward homelessness. Journal of Social Distress and the Homeless, 1(1), 67-79.

Hafer, C. L., \& Sutton, R. (2016) Belief in a just world. In Handbook of social justice theory and research (pp. 145-160). New York: Springer.

Hammond, E. M., Berry, M. A., \& Rodriguez, D. N. (2011). The influence of rape myth acceptance, sexual attitudes, and belief in a just world on attributions of responsibility in a date rape scenario. Legal and Criminological Psychology, 16(2), 242-252. doi:10.1348/135532510X499887

Hill, M. S., \& Fischer, A. R. (2001). Does entitlement mediate the link between masculinity and raperelated variables? Journal of Counseling Psychology, 48(1), 39-50. doi:10.1037/0022-0167.48.1.39

Hockett, J. M., Saucier, D. A., Hoffman, B. H., Smith, S. J., \& Craig, A. W. (2009). Oppression through acceptance? Predicting rape myth acceptance and attitudes toward rape victims. Violence against Women, 15(8), 877-897. doi:10.1177/1077801209335489

Hockett, J. M., Smith, S. J., Klausing, C. D., \& Saucier, D. A. (2016). Rape myth consistency and gender differences in perceiving rape victims: A meta-analysis. Violence against Women, 22(2), 139 167. doi:10.1177/1077801215607359

Hogg, M. A., \& Reid, S. A. (2006). Social identity, self-categorization, and the communication of group norms. Communication Theory, 16(1), 7-30. doi:10.1111/j.1468-2885.2006.00003.x

Howard, J. A. (1984). Societal influences on attribution: Blaming some victims more than others. Journal of Personality and Social Psychology, 47(3), 494-505. doi:10.1037/0022-3514.47.3.494

Kanekar, S., Pinto, N. J., \& Mazumdar, D. (1985). Causal and moral responsibility of victims of rape and robbery.Journal of Applied Social Psychology, 15(4), 622-637. doi:10.1111/j.1559-1816.1985.tb00905.x

Kletsina, I. S., \& Ioffe, E. V. (2013). Russian version of the Male Attitude Norms Inventory: the results of primary approbation. Psikhologicheskie Issledovaniya, 6(32), 6. Retrieved from https://psystudy.ru (in Russian)

Kletsina, I. S., \& Ioffe, E. V. (2017). Gendernye normy kak sotsial'no-psikhologicheskii fenomen [Gender norms as a social psychological phenomenon]. Moscow: Prospekt. (in Russian)

Koepke, S., Eyssel, F., \& Bohner, G. (2014). "She deserved it”: Effects of sexism norms, type of violence, and victim's pre-assault behavior on blame attributions toward female victims and approval of the aggressor's behavior. Violence against Women, 20(4), 446-464. doi:10.1177/1077801214528581

Lambert, A. J., \& Raichle, K. (2000). The role of political ideology in mediating judgments of blame in rape victims and their assailants: A test of the just world, personal responsibility, and legitimization hypotheses. Personality and Social Psychology Bulletin, 26(7), 853-863. doi:10.1177/0146167200269010

Lerner, M. J. (1977). The justice motive: Some hypotheses as to its origins and forms. Journal of Personality, 45(1), 1-52. doi:10.1111/j.1467-6494.1977.tb00591.x

Lerner, M. J., \& Miller, D. T. (1978). Just world research and the attribution process: Looking back and ahead. Psychological Bulletin, 85(5), 1030-1051. doi:10.1037/0033-2909.85.5.1030

Levant, R. F., \& Richmond, K. (2008). A review of research on masculinity ideologies using the Male Role Norms Inventory. The Journal of Men's Studies, 15(2), 130-146. doi:10.3149/jms.1502.130

Lipkus, I. M., Dalbert, C., \& Siegler, I. C. (1996). The importance of distinguishing the belief in a just world for self versus for others: Implications for psychological well-being. Personality and Social Psychology Bulletin, 22(7), 666-677. doi:10.1177/0146167296227002

Lönnqvist, J. E., Walkowitz, G., Wichardt, P., Lindeman, M., \& Verkasalo, M. (2009). The moderating effect of conformism values on the relations between other personal values, social norms, moral 
obligation, and single altruistic behaviours. British Journal of Social Psychology, 48(3), 525-546. doi:10.1348/014466608X377396

Luyt, R. (2005). The Male Attitude Norms Inventory-II: A measure of masculinity ideology in South Africa. Men and Masculinities, 8(2), 208-229. doi:10.1177/1097184X04264631

Mahalik, J. R., Locke, B. D., Ludlow, L. H., Diemer, M. A., Scott, R. P., Gottfried, M., \& Freitas, G. (2003). Development of the Conformity to Masculine Norms Inventory. Psychology of Men and Masculinity, 4(1), 3-25 doi:10.1037/1524-9220.4.1.3

Merkurieva, A. (2015, October 21). A ty kak khotela: kak v Rossii obrashchayutsya s zhertvami iznasilovaniya [What did you want? How the victims of rape are treated in Russia]. Afisha Daily. Retrieved from https:/daily.afisha.ru/archive/gorod/people/a-ty-kak-hotela-kak-v-rossiiobrashchayutsya-s-zhertvami-iznasilovaniya (in Russian)

Moore, T. M., \& Stuart, G. L. (2005). A review of the literature on masculinity and partner violence. Psychology of Men and Masculinity, 6(1), 46-61. doi:10.1037/1524-9220.6.1.46

Murnen, S. K., Wright, C., \& Kaluzny, G. (2002). If "boys will be boys," then girls will be victims? A meta-analytic review of the research that relates masculine ideology to sexual aggression. Sex Roles, 46(11), 359-375. doi:10.1023/A:1020488928736

Nartova-Bochaver, S. K., \& Astanina, N. B. (2014). Theories and empirical researches on justice in the foreign personality psychology. Psikhologicheskii Zhurnal, 35(1), 16-32. (in Russian)

Nartova-Bochaver, S. K., Podlipnyak, M. B., \& Hohlova, A. Yu. (2013). Belief in a Just world and mental wellbeing in deaf and hearing youth and adultsts. Klinicheskaya i Spetsial'naya Psikhologiya, 2(3). Retrieved from https://psyjournals.ru/en/psyclin/2013/n3/Nartova_Bochaver_et_al.shtml (in Russian)

Pedersen, S. H., \& Strömwall, L. A. (2013). Victim blame, sexism and Just-world beliefs: A cross-cultural comparison. Psychiatry, Psychology and Law, 20(6), 932-941. doi:10.1080/13218719.2013.770715

Pinciotti, C. M., \& Orcutt, H. K. (2017). Understanding gender differences in rape victim blaming: The power of social influence and just world beliefs. Journal of Interpersonal Violence. Advance online publication. doi:10.1177/0886260517725736.

Pleck, J. H. (1995). The gender role strain paradigm: An update. In R. F. Levant \& W. S. Pollack (Eds.), A nеw psychology of men (pp. 11-32). New York: Basic Books.

Pool, G. J., Wood, W., \& Leck, K. (1998). The self-esteem motive in social influence: Agreement with valued majorities and disagreement with derogated minorities. Journal of Personality and Social Psychology, 75(4), 967-975.

Postmes, T., Spears, R., Lee, A. T., \& Novak, R. J. (2005). Individuality and social influence in groups: Inductive and deductive routes to group identity. Journal of Personality and Social Psychology, 89(5), 747-763. doi:10.1037/0022-3514.89.5.747

Rubin, Z., \& Peplau, L. A. (1975). Who believes in a just world? Journal of Social Issues, 31(3), 65-89. doi:10.1111/j.1540-4560.1975.tb00997.x

Russell, B. L., \& Trigg, K. Y. (2004). Tolerance of sexual harassment: An examination of gender differences, ambivalent sexism, social dominance, and gender roles. Sex Roles, 50(7-8), 565-573. doi:10.1023/B:SERS.0000023075.32252.fd

Sakallı-Uğurlu, N., \& Glick, P. (2003). Ambivalent sexism and attitudes toward women who engage in premarital sex in Turkey. Journal of Sex Research, 40(3), 296-302. doi:10.1080/00224490309552194

Sakall1-Uğurlu, N., Yalçın, Z. S., \& Glick, P. (2007). Ambivalent sexism, belief in a just world, and empathy as predictors of Turkish students' attitudes toward rape victims. Sex Roles, 57(11-12), 889-895. doi:10.1007/s11199-007-9313-2 
Sims, C. M., Noel, N. E., \& Maisto, S. A. (2007). Rape blame as a function of alcohol presence and resistance type. Addictive Behaviors, 32(12), 2766-2775. doi:10.1016/j.addbeh.2007.04.013

Smith, K. B. (1985). Seeing justice in poverty: The belief in a just world and ideas about inequalities. Sociological Spectrum, 5(1-2), 17-29. doi:10.1080/02732173.1985.9981739

Strelan, P. (2007). The prosocial, adaptive qualities of just world beliefs: Implications for the relationship between justice and forgiveness. Personality and Individual Differences, 43(4), 881-890. doi:10.1016/j.paid.2007.02.015

Sutton, R. M., \& Douglas, K. M. (2005). Justice for all, or just for me? More evidence of the importance of the self-other distinction in just-world beliefs. Personality and Individual Differences, 39(3), 637-645. doi:10.1016/j.paid.2005.02.010

Thompson, E. H. Jr., \& Bennett, K. M. (2015). Measurement of masculinity ideologies: A (critical) review. Psychology of Men and Masculinity, 16(2), 115-133. doi:10.1037/a0038609

Thompson, E. H. Jr., \& Pleck, J. H. (1986). The structure of male role norms. American Behavioral Scientist, 29(5), 531-543. doi:10.1177/000276486029005003

Tomaka, J., \& Blascovich, J. (1994). Effects of justice beliefs on cognitive appraisal of and subjective physiological, and behavioral responses to potential stress. Journal of Personality and Social Psychology, 67(4), 732-740. doi:10.1037/0022-3514.67.4.732

Truman, D. M., Tokar, D. M., \& Fischer, A. R. (1996). Dimensions of masculinity: Relations to date rape supportive attitudes and sexual aggression in dating situations. Journal of Counseling and Development, 74(6), 555-562. doi:10.1002/j.1556-6676.1996.tb02292.x

Valor-Segura, I., Expósito, F., \& Moya, M. (2011). Victim blaming and exoneration of the perpetrator in domestic violence: The role of beliefs in a just world and ambivalent sexism. The Spanish Journal of Psychology, 14(1), 195-206. doi:10.5209/rev_SJOP.2011.v14.n1.17

Van der Bruggen, M., \& Grubb, A. (2014). A review of the literature relating to rape victim blaming: An analysis of the impact of observer and victim characteristics on attribution of blame in rape cases. Aggression and Violent Behavior,19(5), 523-531. doi:10.1016/j.avb.2014.07.008

Willis, C. E., Hallinan, M. N., \& Melby, J. (1996). Effects of sex role stereotyping among European American students on domestic violence culpability attributions. Sex Roles, 34(7), 475-491. doi:10.1007/BF01545027

Yamawaki, N., Ostenson, J., \& Brown, C. R. (2009). The functions of gender role traditionality, ambivalent sexism, injury, and frequency of assault on domestic violence perception: A study between Japanese and American college students. Violence Against Women, 15(9), 1126-1142. doi:10.1177/1077801209340758

Zuckerman, M. (1975). Belief in a just world and altruistic behavior. Journal of Personality and Social Psychology, 31(5), 972-976. doi:10.1037/h0076793

Zuckerman, M., \& Gerbasi, K. C. (1977). Belief in a just world and trust. Journal of Research in Personality, 11(3), 306-317. doi:10.1016/0092-6566(77)90039-3

Elena V. Ulybina - professor, Department of General Psychology, Institute of Social Sciences, Russian Academy of National Economy and Public Administration, DSc in Psychology.

Research Area: psychology of religion, tolerance to uncertainty, identity psychology, gender psychology, personality psychology, general psychology.

E-mail: evulbn@gmail.com 